\title{
BIM Based Facility Condition Assessment
}

\author{
Faisal Faqih \\ f.faqih@connect.polyu.hk \\ Department of Building and Real Estate, Hong Kong Polytechnic University, Hong Kong S.A.R, China \\ Tarek Zayed \\ tarek.zayed@polyu.edu.hk \\ Department of Building and Real Estate, Hong Kong Polytechnic University, Hong Kong S.A.R, China \\ Ehab Soliman \\ ehab.solimanmoursi@ku.edu.kw \\ Civil Engineering Department, College of Engineering and Petroleum, Kuwait University, Kuwait
}

\begin{abstract}
Current practices of using traditional methods of managing data using spreadsheets or hard paper copies for various building data, are commonly being used during building inspection and condition assessment. Building Information Modelling (BIM) can immensely help in solving problems of facility inspection by generating and managing digital representation of the physical and functional characteristics of a facility. This paper describes a model, which is developed to integrate the physical and environmental conditions of a facility on a BIM platform. In this study, factors influencing physical condition and environment condition of the building were identified. Building defects which causes physical deterioration of the building component reduces the ability to perform its intended designed function while environmental condition influences the comfort and health of occupants or users of the building. It is imperative to understand that physical and environment condition of the building are both of vital importance for safety, health and comfort of building users. Factors affecting physical and environment of building were used to develop proposed condition assessment model. Using this proposed model periodic general condition assessment can be performed and correspondingly deterioration graph can be generated for the facility over period of time. Based on inspection data and condition assessment models, building performance can be analyzed for future preventive maintenance.
\end{abstract}

Keywords: Facility management; Building inspection; Condition assessment; BIM

\section{INTRODUCTION}

Facility Managers are responsible for management, operation \& maintenance of buildings which influences the total life cycle cost of building. International Facility Management Association (IFMA) defines Facility Management as, 'A profession that encompasses multiple disciplines to ensure functionality, comfort, safety and efficiency of the built environment by integrating people, place, process and technology'. Facility Managers are also responsible for health, safety and space management ensuring the owner or organization fulfil its obligation to those who use the workspace and are likely to be affected by its operation. Facility management thus have deep impact on efficiency of the workplace, compliance of regulations, local environment and financially to the 
owner or organization. Physical deterioration of building reduces the ability of building to perform it's intended function (Grussing, Uzarski \& Marrano, 2009).

Facilities managers need to identify effect of deterioration in order to prepare corrective and preventive maintenance plans. This task is difficult because of the complex interaction and interdependencies between different building components \& systems. This research aims to use Building Information Modelling (BIM) as a tool for facility condition assessment by using a model which integrates the physical and environmental conditions as well as solve the problem of management of large amount of data generated in condition assessment of large facility.

The aim of this research is to develop a model for facility condition assessment using Building Information Modelling (BIM) as tool for management of data generated during building inspection. The objectives of this research are to identify critical factors, which affects physical building condition and environmental condition of the building. This study proposes a condition assessment model based on building defects. This study further developed an application program to integrate the physical \& environmental conditions of a facility linked with BIM model in Rivet software.

\section{RESEARCH METHODOLOGY}

The research methodology adopted for this study can be described in following steps, which were carried out as follows: Literature review; Identification of critical factors affecting building condition; Develop condition assessment model; Develop application program as an API for Rivet software; Testing and validation of proposed model. For this study, literature search was carried out in major scientific research databases such as Web of Science, Scopus, ASCE Online Library, Science Direct, Google Scholar etc. as well as repositories of universities. It was imperative to identify first what are the factors which affects the physical and environmental building condition. Condition assessment model was developed after identification of factors, which influence the condition of the building. This condition assessment model was developed into an application program as a API for Rivet software, which is one of the extensively used BIM software package. A 3D BIM model was developed for testing and validation of condition assessment model. The development of condition assessment model is examined, analysed and discussed. This paper is concluded with potential benefits of using BIM for facility condition assessment.

\subsection{Literature Review}

Literature review reveals that irrespective of age of the building, defects occur in different forms and to various extents in all types of buildings (Buildings Department, 2002; Yacob, Ali \& Peng, 2016). Building defects can create hazards leading to serious or fatal injuries. Classification of building defects into categories is useful for identifying the type of defect and to estimate probable causes and its recurrence (Haryati, Kharizam, Zainol \& Othman, 2016). Most defects can, at their early stages, be discovered through visible or detectable symptoms. If not promptly rectified, minor defects can develop into serious ones, causing failure or sudden collapse, endangering lives and becoming costlier to rectify (Ahzahar, Karim, Hassan \& Eman, 2011; Buildings Department, 2002). Rafaela and Núria (2018) in their study found out that cracking, water leakage 
are the most common defects for building elements, while leakage and corrosion were more often found in plumbing system. Sometimes one defect can cause other building defect to appear. Othman et al. (2015) in their study found out that moisture problem in a hospital building has cascading effect and leads to several other building defects such as peeling paint, blistering of wallpaper, staining, discoloration, watermarks, mold growth, corrosion on different building elements such a roof, wall, ceiling and floors. Previous studies have noted common building defects such as cracks, water leakage, corrosion etc. which indicates that these defects across different countries are similar in nature which affect physical building condition, however these defects may originate due to different reasons (Chong \& Low, 2006; Kian, 2004; Othman et al., 2015; Suffian, 2013).

\subsection{Critical Factors Affecting Building Condition}

To identify the current state of the building, building stakeholders conduct condition assessment to make appropriate decision for repair and maintenance. During condition assessment if building defects are just identified without finding the source of the defect will lead to reoccurrence of the defect even after repair. To identify the source of building defects it is essential to recognize the factors, which cause them. Building inspection personnel must know different factors or agents, which influences the condition of the building in order to conduct effective condition assessment. Different research concluded that building defects could be attributed to various factors. This study identifies the factors, which influence physical condition and environment condition of the building. According to ISO 19208:2016, major agents affecting physical condition of building or its components can be classified into five types namely Mechanical agents, Electromagnetic agent, Thermal, Chemical and Biological agents. While four main categories which influence the environment condition of the building are Indoor Air Quality (IAQ), Thermal environment, Acoustics and Lighting as per (ASHRAE Guideline 10, 2016).

\subsection{Factors Affecting Physical Condition of the Building}

The soundness of the building is measured by assessing the physical condition of the building. It is important to be cognizant of the factors which influences the building condition in order to assess the correct building diagnosis during condition survey. Various external and factors affect physical condition of the building during its life span. According to ISO 19208:2016 major agents affecting building or its components can be classified into five types namely Mechanical agents, Electro-magnetic agent, Thermal, Chemical and Biological agents. Mechanical loads may include gravity loads like snow loads and dead loads etc. can cause structural failure, loss of function or both. Super imposed forces or restrained deformations such as ice formations, expansion due to heat or contraction due to cold, creep; shrinkage can also cause failure or loss of function or cracks. Building can also be subjected to kinetic energy such as impact loads, storm, or earthquake similarly disturbance from man-made activity such as vibrations from tunneling near building or machine vibrations can also severely affect the strength of the building or its components which may cause structural failure. Solar or ultraviolet radiations, radioactive radiations can cause heating of the building and degradation of building material (Paulo, Branco \& de Brito, 2014). Electricity due to lightning can also seriously harm the building in case of lightning strike on the building. Magnetic fields 
can also affect the building components. Extreme levels of temperatures such as heat, frost or fire can also severely affect the building's appearance, loss of function or may cause structural failure (Lin \& Scott, 2006). Chemical agents source can be waters and solvents from air humidity or ground water (Othman et al., 2015); acids can be from bird droppings, vinegar; salts such as chlorides, nitrates, phosphates; oxidizing agents such as disinfectants, bleach; reducing agent like ammonia, sulphides can also affect the condition of components of building by degrading the building material. Biological agents such as vegetable and microbial agents e.g. plant roots, bacteria, molds and fungi can affect the building or its components. Animals such as rodents, birds, worms or rodents can also affect the building condition by contaminating or degrading the material.

\subsection{Factors Affecting Environmental Condition of Building}

People spend a large part of their life inside the building hence it is essential to identify the factors which affects the environment of the building. According to ASHRAE Guideline 10 (2016) the four main categories which influence the environment condition of the building are Indoor Air Quality (IAQ), Thermal environment, Acoustics and Lighting. The quality of air inside the buildings is a contributing factor for healthy life and wellbeing of people who spend a large part of their life inside buildings (World Health Organization, 2010). Poor indoor air quality can lead to discomfort, ill health, and, in the workplace, absenteeism and lower productivity (Al Horr et al., 2016). Good indoor air quality safeguards the health of the building occupants and contributes to their comfort and well-being. According to ASHRAE 62.1 (2016) acceptable indoor air quality is defined as "air in which there are no known contaminants at harmful concentrations as determined by cognizant authorities and with which a substantial majority $(80 \%$ or more) of the people exposed do not express dissatisfaction". Children, elderly and those with existing respiratory or heart disease are more susceptible to the effects of indoor environment quality. Indoor environment condition has several health effects on humans such as sore throat, headache, eyes irritation, nose irritation, dizziness, fatigue etc. after exposure to high concentrations of indoor air pollutants (IAQMG HKSAR, 2019).

Parameters such as temperature, humidity, and air movement are important indoor air quality parameters as they could affect people's perception of the indoor air quality (Arif, Katafygiotou, Mazroei, Kaushik \& Elsarrag, 2016). The level of some of the indoor air pollutants could also be affected by temperature and humidity (ASHRAE Guideline 10, 2016). However thermal comfort may differ from person to person based on their gender, age and personal preferences (Arif et al., 2016), according to ASHRAE 55 (2017) thermal comfort is defined as "that condition of mind that expresses satisfaction with the thermal environment and is assessed by subjective evaluation".

Thermal comfort is directly affected by air temperature. There are various factors, which can influence the temperature of a room such as air conditioning, heat sources from solar heat, lighting, computer or any other heat dissipating machines in the room. If a room is considerably large the same room may have different room temperatures based on air conditioning outlet, window location etc. Since the temperature evaluation is subjective, different people may have different level of comfort in the same room with same temperature. This difference in temperature perception of comfort will depend of various factors such as gender, age, season activity level etc.(ASHRAE 55, 2017; Kim, 
de Dear, Cândido, Zhang \& Arens, 2013; Maykot, Rupp \& Ghisi, 2018). Humidity in air affects human body's ability to lose body heat through perspiration, which in turn influences thermal comfort of people. High humidity encourages growth of fungi on building furnishings and fabrics while low humidity can cause eyes, nose throat to dry which can lead to discomfort and irritation (IAQMG HKSAR, 2019). Low humidity in the room can also cause static electricity generation, which can affect electronic components and discomfort among the occupants of the room (ASHRAE 55, 2017).

Building acoustic quality can have great impact on occupant's comfort level. Noise is unwanted sound and its perception is very subjective from person to person. Different factors influence in noise perception such as magnitude, duration or time of occurrence. Music to one's ear may be noise to another. The characteristics of sound in a room is also affected by surfaces in the room that might absorb, reflect, or transmit sound (ASHRAE Handbook, 2017). Adequate and appropriate lighting is required to perform visual tasks efficiently. Good lighting inside the building is also essential for visual comfort of the occupants or users of the building. The degree of visibility and comfort required in a wide range of work places is governed by the type and duration of the activity (BS EN 12464-1, 2011).

\subsection{Proposed Condition Assessment Model}

In this proposed condition assessment model, each space in a building is assessed simultaneously for both physical condition as well as environmental condition. Each space in buildings can be clustered into groups according to user defined building hierarchy groups such as classrooms, corridors, laboratories, offices, corridors, staircase etc. Same building components may have different relative weightage in different buildings according to their functional use. Hence, there should be flexibility in assigning relative weightage of building components according to the requirements and importance of components of building. In this proposed model user is allowed to define relative weightage of building components according to their importance in the building. Analytical Hierarchy Process (AHP) is used for calculating relative weightage of different building components based on pairwise comparison between them. Proposed condition assessment model is defect-based model in which each building component is assessed based on damage, which has occurred due to various building defects. The condition assessment process of proposed model is as shown in figure 1. The four main assessment criteria considered for this condition assessment model are Safety; Criticality of Element / Component (Importance); Operational Efficiency (Functional use); and Appearance (Aesthetics).

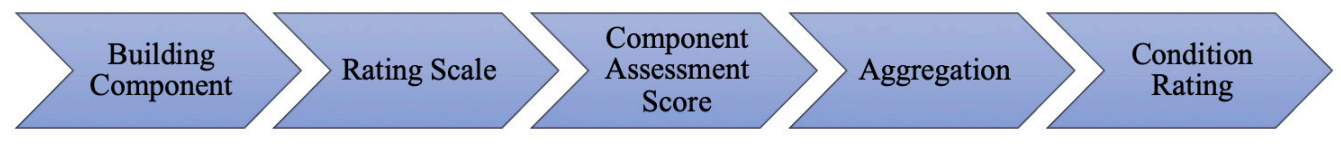

Figure 1: Condition assessment process for proposed model

Scale of 1-10 is used to assess the condition of building component for physical condition based on visual inspection. An average of scores of individual criteria is used for further calculations. 
Final consolidated rating is calculated by aggregating the products of individual component ratings with their relative weights as shown in equation 1.

$$
R_{P h y}=\sum_{i=1}^{m} S_{i} W_{i}
$$

where, $R_{\text {Phy }}=$ final consolidated physical rating

$S_{i}=$ Average of score for individual assessment criteria based on scale of 1-10

$W_{i}=$ Relative weightage of component as defined using AHP

Similarly, for environmental condition assessment for a particular room/space reading from instruments measuring concentrations of carbon dioxide, carbon monoxide, and ozone representing Indoor air quality; humidity and temperature readings; lighting intensity and sound decibels are used for calculation. These reading are converted into Utility Values using from on a common scale of $0-1$ by using permissible limits given by respective guidelines and codes as follows: IAQMG HKSAR (2019) for Indoor Air Quality readings, Thermal Comfort as per (ASHRAE 55, 2017), Acoustics as per ASHRAE Handbook (2017) and lighting of room as per (BS EN 12464-1, 2011). Final consolidated rating is calculated by aggregating the products of individual utility values with their relative weights as shown in equation 2 .

$$
R_{E n v}=\sum_{j=1}^{n} U_{j} W_{j}
$$

where, $R_{E n v}=$ final consolidated environmental rating

$U_{j}=$ Average utility value converted from instrument readings

$W_{j}=$ Relative weightage of component as defined using AHP

\subsection{BIM Application Program}

Building Information Modelling (BIM) is the process through which essential facility information is captured, maintained, and shared digitally in a set of integrated BIM models. Inspection of large number of building components is a huge task, sorting them in groups and categories and building hierarchy is required for easier management during condition assessment. Building Information Modelling (BIM) can help immensely in solving problems of facility managers by generation and management of digital representation of the physical and functional characteristics of a facility. To test and validate the condition assessment model for this study, a 3D BIM model of entire floor of a building was created using Rivet software.

The program developed for this study can be accessed as Add-Ins in rivet software, which can retrieve the tagged room from BIM model. After filtering the tagged room, the groups as defined by user can be assigned relative weights according to user defined importance of the space inside the building using Analytical Hierarchy Process (AHP). These relative weights will be further used for calculation. Each space then can be assessed based on four criteria as per proposed model on a scale of 1-10. Similarly, the 
environmental readings from the instruments can be entered for the same room/space for IAQ, Humidity, Temperature, Sound levels, and lighting intensity. Additionally, individual remarks and photos of the room/space can be attached along with the readings. On clicking analysis, all the entered values are processed and converted to their respective utility values and final aggregated ratings are calculated and graphically presented.

\section{RESULTS}

Rivet software by Autodesk was used to create BIM model as this software is widely used in industry. Rivet also has provision for API (Application Programming Interface) which gives user to extract data from BIM model to another program for further analysis. Using C\# language in Microsoft Visual Studio, a program was developed and linked with API of Rivet to extract data from existing BIM model. To analyze and run the program requisite input of rating scores of building component and instrument readings for environment condition analysis is required by user. Condition assessment for a particular date of each user-defined groups can be graphically presented. Deterioration of entire facility condition over a period of time can also be generated as shown in Figure 2.

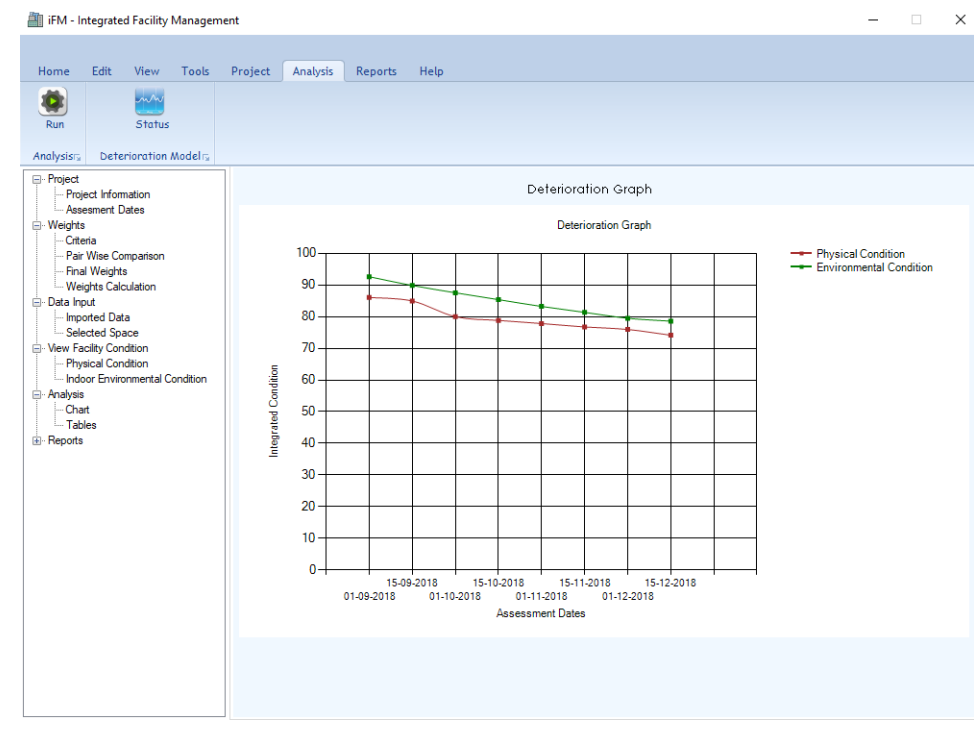

Figure 2: Deterioration graph of facility condition generated from program

The reason to use API of Rivet software for development of computer program is that the same Rivet BIM model can also be used by facility managers for other services such as space allocation management, building services management, clash detection while operation \& maintenance of the facility, controlling expenditure cost by managing resources efficiently and also for meeting statutory regulatory compliances. Existing BIM models can be customized according to this program requirement to aid in inspection of building component assessment and correspondingly a deterioration model can be generated for the facility using the program developed. Further deterioration graph can be generated based on condition assessment of different period of time. Deterioration 
graph based on condition assessment can serve as a benchmark for comparison for the building at different period of time. Periodic inspection of building and corresponding condition assessment will be useful to quantify the severity of deterioration of building components in order to prioritize interventions and decision making in maintenance during service life of the building. This proposed building condition assessment model can serve as key performance indicators (KPIs) which can help stakeholders to make better choices in operation, maintenance and repair of the building facilities.

\section{DISCUSSION}

The condition of majority of building starts declining ever since it is started being used due to external factors such as weather or factors such as inadequate maintenance along with general wear and tear (Wahida, Milton, Hamadan, Lah \& Mohammed, 2012). There is a complex inter relationship between different building components and systems which depends on intended design of the building as a whole (Uzarski, Hicks \& Zahorak, 2002). Buildings are composed of large number of inter-dependant elements, components and systems with complex interrelationship. Physical deterioration of the building reduces its ability to perform its intended designed function while environmental condition influences the comfort and health of occupants or users of the building. It is imperative to understand that physical and environment condition of the building are both of vital importance for safety, health and comfort of building users. In this study, factors influencing physical condition and environment condition of the building were identified and used to develop proposed condition assessment model. These factors individually or in combination of the others may lead to growth of defects in various building elements, which can have cascading effects leading to deterioration of the whole building. It is important to understand factors, which influence building condition to accurately identify probable cause of building defect under consideration for further correct diagnosis during inspection. Building defects if remain unable to detect due to incorrect diagnosis of source of problem may further worsen the condition of the building. In this study, different factors, which influence the condition of the building, were identified and BIM as interface is used to run proposed condition assessment model.

\section{CONCLUSION}

The aim of present research is to enable sustainable facility management and improve efficiency by integrating the complex interaction and interdependency between physical \& environmental conditions of different components \& systems of the facility. Cognizance of condition of building periodically can be helpful to building managers to intervene earlier on detection of minor defects. Taking appropriate remedial action as preventative maintenance could reduce time and cost required for major repair costs due to propagation of minor defects into major defects. This study can help building stakeholders and building inspection personnel to conduct condition assessment of the building using BIM as a tool. The computer program developed in this study has an advantage that it can be implemented into existing BIM models in Rivet software for facility condition assessment via Application Programming Interface (API). Future buildings constructed using BIM will generate the necessity of application of BIM in facility management. 


\section{REFERENCES}

Ahzahar, N., Karim, N. A., Hassan, S. H. \& Eman, J. (2011). A study of contribution factors to building failures and defects in construction industry. Procedia Engineering, 20, 249-255.

Al Horr, Y., Arif, M., Kaushik, A., Mazroei, A., Katafygiotou, M. \& Elsarrag, E. (2016). Occupant productivity and office indoor environment quality: A review of the literature. Building and Environment, 105, 369-389.

Arif, M., Katafygiotou, M., Mazroei, A., Kaushik, A. \& Elsarrag, E. (2016). Impact of indoor environmental quality on occupant well-being and comfort: A review of the literature. International Journal of Sustainable Built Environment, 5(1), 1-11.

ASHRAE 55. (2017). Thermal Environmental Conditions for Human Occupancy. Atlanta, GA: American Society of Heating Refrigerating and Air-Conditioning Engineers (ASHRAE).

ASHRAE 62.1. (2016). Ventilation for Acceptable Indoor Air Quality. Atlanta, GA: American Society of Heating Refrigerating and Air-Conditioning Engineers (ASHRAE).

ASHRAE Guideline 10. (2016). Interactions Affecting the Achievement of Acceptable Indoor Environments. American Society of Heating Refrigerating and Air-Conditioning Engineers (ASHRAE).

ASHRAE Handbook. (2017). ASHRAE Handbook, Chapter 8 Sound and vibration. American Society of Heating Refrigerating and Air-Conditioning Engineers (ASHRAE).

BS EN 12464-1. (2011). Light and lighting — Lighting of work places Part 1 : Indoor work places. British Standard Institution.

Buildings Department. (2002). Building Maintenance Guidebook. Buildings Department, Hong Kong.

Chong, W. K. \& Low, S. P. (2006). Latent building defects: causes and design strategies to prevent them. Journal of Performance of Constructed Facilities, 20(3), 213-221.

Grussing, M. N., Uzarski, D. R. \& Marrano, L. R. (2009). Building Infrastructure Functional Capacity Measurement Framework. Journal of Infrastructure Systems, 15(4), 371-377. https://doi.org/10.1061/(ASCE)1076-0342(2009)15:4(371).

Haryati, M. I., Kharizam, I., Zainol, H. \& Othman, M. F. (2016). Tracking architectural defects in university building in Malaysia. MATEC Web Conferences, International Building Control Conference (IBCC), 66, 00017. Retrieved from https://doi.org/10.1051/ matecconf/20166600017.

IAQMG HKSAR. (2019). Guidance Notes for the Management of Indoor Air Quality in Offices and Public Places. Retrieved from https://www.iaq.gov.hk/media/82253/gn officeandpublicplace_eng-2019.pdf.

ISO 19208. (2016). Framework for specifying performance in buildings. International Organization for Standardization (ISO).

Kian, P. S. (2004). A review of factors affecting building defects in Singapore. Dimensi Teknik Sipil, 3(2), 64-68.

Kim, J., de Dear, R., Cândido, C., Zhang, H. \& Arens, E. (2013). Gender differences in office occupant perception of indoor environmental quality (IEQ). Building and Environment, 70, 245-256. https://doi.org/https://doi.org/10.1016/j.buildenv.2013.08.022.

Lin, J. \& Scott, D. (2006). Assessment of Significances of Building Failure Induced by Foundation Failure: Facade Failure, and Moisture Problem. Architectural Engineering Conference, 1-13. 
https://doi.org/doi:10.1061/40798(190)26.

Maykot, J. K., Rupp, R. F. \& Ghisi, E. (2018). A field study about gender and thermal comfort temperatures in office buildings. Energy and Buildings, 178, 254-264. https://doi.org/https:// doi.org/10.1016/j.enbuild.2018.08.033.

Othman, N. L., Jaafar, M., Harun, W. M. W. \& Ibrahim, F. (2015). A case study on moisture problems and building defects. Procedia-Social and Behavioral Sciences, 170, 27-36.

Paulo, P. V., Branco, F. \& de Brito, J. (2014). BuildingsLife: A building management system. Structure and Infrastructure Engineering, 10(3), 388-397. https://doi.org/10.1080/15732479 .2012.756919.

Rafaela, B. \& Núria, F. (2018). Building Inspection System for Evaluating the Technical Performance of Existing Buildings. Journal of Performance of Constructed Facilities, 32(5), 4018073. https://doi.org/10.1061/(ASCE)CF.1943-5509.0001220.

Suffian, A. (2013). Some common maintenance problems and building defects: Our experiences. Procedia Engineering, 54, 101-108.

Uzarski, D., Hicks, D. \& Zahorak, J. (2002). Building and Building Component Condition and Capability Metrics. Applications of Advanced Technologies in Transportation, 441-448. https://doi.org/doi:10.1061/40632(245)56.

Wahida, R. N., Milton, G., Hamadan, N., Lah, N. M. I. B. N. \& Mohammed, A. H. (2012). Building Condition Assessment Imperative and Process. Procedia - Social and Behavioral Sciences, 65, 775-780. https://doi.org/https://doi.org/10.1016/j.sbspro.2012.11.198.

World Health Organization (2010). Guidelines for Indoor Air Quality: Selected Pollutants. https://doi.org/10.1186/2041-1480-2-S2-I1.

Yacob, S., Ali, A. S. \& Peng, A. Y. C. (2016). Building Condition Assessment: Lesson Learnt from Pilot Projects. MATEC Web of Conferences, International Building Control Conference (IBCC), 66, 72. Kuala Lumpur, Malaysia: EDP Sciences. 